\title{
Desafíos en movilidad internacional y desarrollo de competencias psicosociales emprendedoras
}

Challenges in international mobility and development of entrepreneurial psychosocial competences

\section{Volumen 20, Número 1 \\ Enero - Abril \\ pp. 1-33}

\author{
Yamila Silva Peralta \\ María Emilia Rompato
}

Citar este documento según modelo APA

Silva Peralta, Yamila y Rompato, María Emilia. (2020). Desafíos en movilidad internacional y desarrollo de competencias psicosociales emprendedoras. Revista Actualidades Investigativas en Educación, 20(1), 1-33. Doi. 10.15517/aie.v20i1.39924 


\title{
Desafíos en movilidad internacional y desarrollo de competencias psicosociales emprendedoras
}

\author{
Challenges in international mobility and development of entrepreneurial psychosocial
} competences

\author{
Yamila Silva Peralta ${ }^{1}$ \\ María Emilia Rompato²
}

\begin{abstract}
Resumen: El presente artículo forma parte de un proyecto de investigación que tiene por objetivo conocer y analizar las competencias psicosociales emprendedoras que se generan en el ámbito de la educación superior. Así entonces, se parte de la dimensión de la internacionalización en las Instituciones de Educación Superior (IES), este estudio presenta resultados sobre los desafíos que el estudiantado de grado declara transitar en su experiencia de movilidad internacional y el consecuente desarrollo de las mencionadas competencias. Mediante una metodología cualitativa, con un diseño fenomenológico y un enfoque etnometodológico fueron realizadas entrevistas en profundidad a una muestra intencional de 36 estudiantes de grado de la Universidad Nacional de Mar del Plata, Argentina, quienes llevaron a cabo una movilidad internacional en los años 2016, 2017 o 2018. Las entrevistas versaron principalmente sobre la caracterización de los momentos pre movilidad, movilidad y post movilidad. Los resultados demuestran que debido a dicha experiencia el estudiantado sobrelleva desafíos culturales, lingüísticos, burocráticos, económicos y académicos, a partir de los cuales logran adquirir una mayor apertura mental ante experiencias nuevas, autoconocimiento, autonomía, capacidad resolutiva y una mirada crítica e integral. Se concluye que dicha experiencia no solo surte un efecto positivo a nivel individual, académico y profesional en el grupo de estudiantes que la realiza, sino que también es una importante estrategia institucional para reforzar la responsabilidad social universitaria, de cara a dar respuestas a las nuevas problemáticas sociales.
\end{abstract}

Palabras clave: internacionalización, educación superior, movilidad estudiantil, competencias.

Abstract: The present article is part of a research project whose objective is to know and analyze the entrepreneurial psychosocial competences generated in the field of higher education. Thus, based on the dimension of internationalization in higher education institutions (HEls), this study presents results on the challenges that undergraduate students declare to transit in their experience of international mobility and the consequent development of the mentioned competences. Through qualitative methodology, with a phenomenological design and ethnomethodological approach, in-depth interviews were conducted with an intentional sample of 36 undergraduate students of the National University of Mar del Plata, Argentina, who carried out an international mobility in the years 2016, 2017 or 2018. The interviews dealt mainly with the characterization of pre-mobility, mobility and post-mobility moments. The results show that, due to this experience, students overcome cultural, linguistic, bureaucratic, economic and academic challenges, from which they acquire a greater mental openness to new experiences, self-knowledge, autonomy, resolutive capacity and a critical and integral look. It is concluded that not only this experience has a positive effect at an individual, academic and professional level in the group of students that carries it out, but it is also an important institutional strategy to reinforce the university social responsibility, in order to give answers to the new social troubles.

Key words: internationalization, higher education, student's mobility, skills.

1 Investigadora Asistente, CONICET-Universidad Nacional de Mar del Plata, Argentina. Doctora en Psicología, Universidad de Barcelona, España. Dirección electrónica: yamilasilvaperalta@gmail.com ORCID: https://orcid.org/0000-0003-1917$\underline{3406}$

2 Becaria de Investigación Universidad Nacional de Mar del Plata, Argentina. Licenciada en Sociología, Universidad Nacional de Mar del Plata, Argentina. Dirección electrónica: merompato@gmail.com ORCID: https://orcid.org/0000-0001-6089-2387

Artículo recibido: 25 de junio, 2019

Enviado a corrección: 16 de setiembre, 2019

Aprobado: 18 de noviembre, 2019

Los contenidos de este artículo están bajo una licencia Creative Commons 


\section{Introducción}

En la actualidad, las Instituciones de Educación Superior (en adelante IES) trabajan activamente hacia la consecución de cambios que den respuesta a las demandas sociales, culturales y laborales del mundo contemporáneo. Desde conceptos como los de "multiculturalidad" y "diversidad", que pujan por adentrarse en la malla curricular de las IES, hasta altos niveles de competencia en los mercados laborales, la realidad actual obliga a dichas instituciones a implementar cambios. En el eje de este debate se encuentra la necesidad de aprender y gestionar nuevos conocimientos, habilidades y destrezas (Orantes, 2015). Es decir, se pone en juego un nuevo esquema educacional basado en competencias. Esto queda evidenciado cuando, tanto en el discurso como en los hechos, se enfatiza la importancia de la adquisición de competencias genéricas y específicas para enfrentar las demandas reales que actualmente reclaman el mercado laboral y el desarrollo científico y tecnológico (García Palma, 2013).

Uno de los pilares para dar respuesta a dicha situación es la promoción de una educación internacional, por cuanto es una estrategia capaz de transversalizar la oferta académica y la propuesta curricular, integrando lo local a lo global y viceversa (López Echeverri, 2014). Aunque en los últimos años la cooperación internacional ha aumentado notablemente, específicamente en lo que refiere a actividades de movilidad internacional, sus inicios pueden rastrearse en el Medioevo ${ }^{3}$. Segun Karady (2006), en ese entonces, los flujos internacionales se caracterizaban por ser espontáneos, no institucionalizados y motivados por decisiones culturales y políticas o por oportunidades históricas. Tünnermann Bernheim (2003) afirma que en la actualidad la cooperación internacional responde a nuevos requerimientos de la integración geoeconómica, al fenómeno de la interdependencia económica entre naciones, al cambio tecnológico en la producción, las telecomunicaciones, la informática y el nuevo valor que han adquirido los conocimientos.

Si se analizan los motivos para realizar una experiencia de movilidad internacional se encontrarán, por un lado, las investigaciones de Pons, Pineda Herrero y Moreno Andrés (2007), quienes destacan las motivaciones vinculadas a las características del contexto familiar del estudiante, principalmente al nivel de estudios y actividades laborales de los progenitores; por otra parte, Tene, Preciado y Pérez Cruz (2008) desarrollan los intereses académicos profesionales que motivan una experiencia tal, entre los que se destacan el

3 Vale aclarar que no eran actividades formalizadas como así tampoco lo eran las estructuras estatales que posibilitaban dicha movilidad internacional. 
deseo de aprendizaje o perfeccionamiento de un idioma, el interés por cursar materias que no se ofertan en la universidad de origen y la posibilidad de egresar de las aulas con mayores y mejores cualificaciones para el sector productivo. Finalmente Santiago Ruiz, Zúñiga y Rodríguez (2018), aportan los motivos personales, entre los que se destaca el deseo de buscar nuevas experiencias, vivir nuevos desafíos y conocer otra cultura entre otros. Este tipo de investigaciones son de gran importancia ya que aportan insumos para comprender más acabadamente qué lleva al estudiantado a realizar una movilidad y, por tanto, brinda herramientas para potenciarlo.

Dentro de este espectro de investigaciones, Hernández (2008), Villalón (2017) y Juárez Salomo, Gama Hernández y Cuevas Olascoaga (2019) destacan el perfil de competencias del grupo estudiantil que decide realizar una experiencia de movilidad internacional. Sobre este respecto, Villalón (2017) afirma que realizar una experiencia de ese tipo no tiene únicamente que ver con una decisión basada en la experiencia cultural y personal académica, sino que responde a un deseo y accionar consciente de disponer de un importante capital para mejorar las oportunidades de empleo en sectores cada vez más globalizados del mercado de trabajo.

Hernández (2008) analiza la experiencia de movilidad en estudiantes angloamericanos durante su estadía en universidades mexicanas, y afirma que quien realiza una experiencia de movilidad internacional en el ámbito académico puede adquirir cuatro tipos de impactos: lingüístico, cultural, académico y profesional. Destaca el desarrollo de competencias interculturales y competencias lingüísticas, ambas impactan positivamente en la identidad del alumnado. En el desarrollo de las competencias lingüísticas, sobresale el desarrollo de un segundo idioma en el contexto académico-profesional y el mejoramiento de la fluidez oral. Según este modelo, la competencia intercultural está compuesta por un conjunto de aprendizajes que se integran en tres dimensiones: cultural, cognitiva y afectiva. Además, quienes realizan una movilidad internacional son capaces de mostrar empatía cultural a través del conocimiento de diversos aspectos del país donde estuvieron, e incrementar la capacidad de adaptarse a contextos y situaciones distintas a las que estaban acostumbrados. Por todo esto, se concluye que, a lo largo de su estancia en México, el grupo estudiantil analizado fue capaz de desarrollar habilidades cognoscitivas e intelectuales.

Por último, Juárez Salomo et al. (2019) define como "competencias globales" a aquellas que se fortalecen en escenarios multiculturales y trabajan en un doble sentido. Por 
un lado, fortalecen al grupo de estudiantes, docentes y/o investigadores que realicen una experiencia en movilidad internacional. Por otro lado, ayudan a formalizan e institucionalizar la internacionalización de la educación superior. Entre ellas, la autora destaca: habilidad para el aprendizaje a través de la observación y la escucha, capacidad para trabajar en situaciones difíciles o ambiguas, adaptabilidad e ingenio en ambientes nuevos y desafiantes, manejo de situaciones complejas, entre otras.

El presente trabajo profundiza la corriente antes descripta y se basa en un estudio empírico realizado en estudiantes de grado, participantes de una movilidad internacional, provenientes de la Universidad Nacional de Mar del Plata (en adelante UNMDP), Argentina. El objetivo radica en conocer qué tipo de desafíos vivieron durante la experiencia de una movilidad internacional y qué tipo de competencias genéricas lograron adquirir como consecuencia. Es decir, parte del marco teórico de competencias para analizar los procesos de internacionalización de las IES.

Se espera que los resultados permitan conocer la riqueza de la internacionalización en el plano de la educación superior. Así también, se espera que contribuya, en términos evaluativos, con el área de Relaciones Internacionales de la UNMDP y con cualquier otra universidad que desee replicar la presente experiencia.

El artículo se encuentra estructurado en una sección de revisión teórica, en donde se recorrerán los principales conceptos planteados: internacionalización de la educación superior y competencias psicosociales emprendedoras; posteriormente se encuentra un apartado metodológico, a partir del cual es posible indagar con mayor profundidad el diseño y enfoque metodológico seleccionado, población y muestra seleccionada, técnicas y procesamiento de los datos. En la sección de resultados se encuentra el desarrollo propiamente investigativo, tanto de los desafíos transitados como de las competencias desarrolladas, con un especial énfasis en su relación. Por último, se encuentran las conclusiones y agradecimientos, en donde se delinean fortalezas y debilidades de la investigación, proyectos a futuro, entre otras cuestiones.

\section{Referente teórico. De las IES nacionales a las IES internacionales}

El concepto de internacionalización ha sido extensamente desarrollado en ámbitos como el de la gestión, aun así, sigue siendo origen de debate y cuestionamientos en lo que atañe a educación superior (De Wit, 1995; Delgado Márquez, Hurtado Torres y Bondar, 2011). Así siguiendo a Knight (1997) es posible decir que las definiciones de 
internacionalización responden a cuatro perspectivas: actividad, competencias, ethos y proceso.

El presente trabajo se adscribe a la definición por competencias que afirma que:

(...) la internacionalización es un proceso de cambio de una IES nacional a una IES internacional, llevando a la inclusión de la dimensión internacional de manera holística, con el fin de mejorar la calidad de enseñanza e investigación, logrando las competencias deseadas. (Soderqvist, 2002, p. 29)

Dicha concepción tiene como marco teórico los aportes de la ONU (Leeds, 2017) que propone como necesaria la adquisición de competencias interculturales que permitan vivir pacíficamente en un mundo globalizado.

La internacionalización de las IES significa no solo la integración de actividades con perspectiva internacional, sino que es un eje transversal que atraviesa todas las dimensiones académicas y directivas de las IES mediante la incorporación de la dimensión internacional e intercultural en la visión y misión, la organización y los procesos administrativos, las actividades y actores de los procesos de formación, la comunidad académica, la investigación, extensión y vinculación universitaria (Aguilera de Drelichman, 2017; Alcón, 2011; Arango y Acuña, 2018; Delgado Márquez et al, 2011; Guido Guido y Guzmán Aguilar, 2012; Guy, 2010; Morresi, Elías y Quartucci, 2018; Rodríguez Betanzos, 2014)4.

La perspectiva de competencias de la dimensión internacional supone, en última instancia, la incorporación de reformas curriculares basadas en competencias, y la redefinición de los campos según los requerimientos de acreditación para un mercado global. Siguiendo a la UNESCO se trata de: aprender a conocer, aprender a hacer, aprender a convivir y aprender a ser (Delors, 1996).

Sin lugar a dudas, una de las estrategias más reconocidas de la internacionalización es la movilidad estudiantil internacional. Esta se define como el traslado físico de un estudiante (de grado o posgrado) de una IES a otra por un período de tiempo con fines académicos (Hernández, Domínguez, Almaraz y Escamilla, 2014; Ramírez y Montañez, 2014; Villalón, 2017). De acuerdo con García Palma (2013), a nivel académico, la movilidad estudiantil es

\footnotetext{
${ }^{4}$ Es interesante destacar que la internacionalización de las IES también engloba el análisis de la "fuga de talentos" latinoamericanos. Es decir, aquellos procesos en donde recursos humanos altamente calificados, en general individuos que poseen doctorados, emigran desde América Latina hacia EEUU o Europa, fruto de las asimetrías sociales, laborales, económicas, etc. entre dichas regiones. Para más información se recomienda Didou Aupetit y Gerard (2009).
} 
propuesta como una mejora de la formación profesional, la movilización de saberes y la estructuración de redes de intercambio. Además, se afirma que la movilidad puede servir también como una estrategia para la renovación de modelos educativos tendientes a formar ciudadanos del mundo, calificados, actualizados, con un profundo sentido de la responsabilidad social y con competencias sociales acordes al mundo globalizado (Sebastian, 2011). La premisa que guía la idea es que cruzar las fronteras geográficas del saber supone un proceso de reaprendizaje a través de la experiencia (Santiago Ruiz et al., 2018).

Latinoamérica no es ajena a esta transformación en la educación superior; se pueden encontrar investigaciones sobre dicha experiencia en países como Colombia, Chile, México, entre otros. Para el caso colombiano, Jaramillo (2003) afirma que, aunque la internacionalización de la educación superior ha crecido y se ha institucionalizado, muchas veces queda librada a su suerte, sin planeamiento estratégico. Para la autora, resulta importante participar de esta actividad, desde el lugar que cada uno tenga, pues esto potencia la democratización del conocimiento. Geldres, Vásquez y Ramos (2013) analizan, desde una metodología cuantitativa, el estado de la educación internacional en la Universidad de Frontera, en Chile, y afirman que, aunque Chile en particular y en América Latina en general, han ganado un importante territorio en la distribución de las plazas para movilidades internacionales, el estudiantado sigue "mirando hacia afuera", especialmente a Europa. Aunque sin ser objetivo de la investigación, los autores destacan también la importancia de continuar investigaciones en el camino de la relación entre experiencias de movilidad internacional y desarrollo de competencias para el sector profesional. Por último, en México, Vázquez del Mercado (2009) destaca las ventajas que la movilidad internacional tiene para el alumnado, al afirmar que al realizar dicha experiencia esta población adquiere una formación intercultural que les permite establecer diálogos constructivos y proponer significados e interpretaciones conjuntas.

En lo que respecta al Cono Sur, es posible decir que, aunque han surgido programas de Cooperación Sur- Sur, como programas que privilegian el desarrollo endogámico, horizontal y co- participativo, en vistas del fomento de la integración regional (Lechini 2009), muchas veces la actividad no logra adquirir el enfoque que debiera. Según Aguilera de Drelichman (2017), uno de los mayores problemas es el hecho de que el fomento a la internacionalización es muchas veces una actitud reactiva ante las oportunidades y no una toma real de conciencia de los beneficios por parte de la comunidad universitaria. 
Ciertamente, esta idea encuentra correlato con las propuestas por Gacel (2000), quien afirma que la internacionalización no tiene prioridad en las agendas de educación superior, ya que carece de un planeamiento estratégico con objetivos a corto, mediano y largo plazo, de diseño de políticas y estructuras sistemáticas y profesionales ${ }^{5}$.

En lo que respecta al área de Relaciones Internacionales de la UNMDP, es posible hablar de un trabajo sistemático y sostenido en el tiempo, lo cual ha devenido en la adhesión a múltiples redes, organizaciones y programas del campo de la internacionalización. Estas adhesiones son de diversa envergadura y proporcionan relaciones tanto en el plano latinoamericano como en el europeo. A continuación, se precisan gráficamente mediante la Tabla 1.

Tabla 1

Adhesión de la UNMDP- Argentina a redes y programas internacionales

\begin{tabular}{|c|c|}
\hline $\begin{array}{l}\text { Participación en redes y organizaciones } \\
\text { del campo de la internacionalización }\end{array}$ & $\begin{array}{l}\text { Programas de movilidades internacionales } \\
\text { con partners latinoamericanos y europeos }\end{array}$ \\
\hline $\begin{array}{l}\text { AUGM (Asociación de Universidades del } \\
\text { Grupo Montevideo) 2008- actualidad }\end{array}$ & $\begin{array}{l}\text { Programa Escala AUGM (Argentina, Brasil, } \\
\text { Bolivia, Chile, Paraguay, Uruguay) } \\
\text { actualidad }\end{array}$ \\
\hline $\begin{array}{l}\text { PILA (Programa de Intercambio Académico } \\
\text { Latinoamericano) 2017- actualidad }\end{array}$ & $\begin{array}{l}\text { Programa PILA (Argentina, Colombia, México) } \\
\text { 2008- actualidad }\end{array}$ \\
\hline $\begin{array}{l}\text { AIESAD (Asociación lberoamericana de } \\
\text { Educación Superior) 2005- actualidad }\end{array}$ & $\begin{array}{l}\text { Programa ARFITEC (Francia-Argentina) 2015- } \\
\text { actualidad }\end{array}$ \\
\hline $\begin{array}{l}\text { ATEI (Asociación de Televisión Educativa } \\
\text { lberoamericana) 2005- actualidad }\end{array}$ & $\begin{array}{l}\text { Programa ALFAGRI (Francia-Argentina) 2015- } \\
\text { actualidad }\end{array}$ \\
\hline 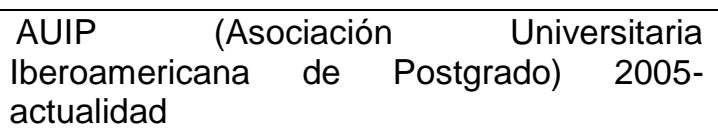 & $\begin{array}{l}\text { Programa MARCA (Argentina, Brasil, Bolivia, } \\
\text { Colombia, Paraguay, Uruguay) 2011- actualidad }\end{array}$ \\
\hline $\begin{array}{l}\text { UDUAL (Unión de Universidades de } \\
\text { América Latina) 2019- actualidad }\end{array}$ & $\begin{array}{l}\text { Programa ALEARG (Alemania-Argentina) 2008- } \\
\text { actualidad }\end{array}$ \\
\hline $\begin{array}{l}\text { OUI (Organización Universitaria } \\
\text { Interamericana) 2005- actualidad }\end{array}$ & $\begin{array}{l}\text { Programa IDEAR (Alemania-Argentina) 2014- } \\
\text { actualidad }\end{array}$ \\
\hline
\end{tabular}

Fuente: Elaboración propia, 2019.

${ }^{5}$ Si bien la autora refiere al caso mexicano al hacer dicha afirmación, la bibliografía consultada muestra una realidad similar en América Latina en general. 
Por último, y como información complementaria, es de remarcar que durante el año 2018 menos del $0,1 \%$ del estudiantado de la UNMDP ha podido movilizarse internacionalmente en el marco de programas de movilidad gestionados desde el Área de Relaciones Internacionales (32 estudiantes salientes: 9 en el primer cuatrimestre y 23 en el segundo cuatrimestre). Considerando los últimos 4 años, la cantidad de estudiantes movilizados internacionalmente se ha mantenido a lo largo del tiempo (Ver Figura 1). En el 2018 y para el 2019, se incrementaron "levemente" las plazas de movilidad estudiantil a través del Programa de Intercambio Académico Latinoamericano (PILA) en 3 plazas para el 2018 y 8 plazas para el 2019.

Figura 1

Número de estudiantes movilizados internacionalmente por año, UNMDP-Argentina. Período 2016-2019

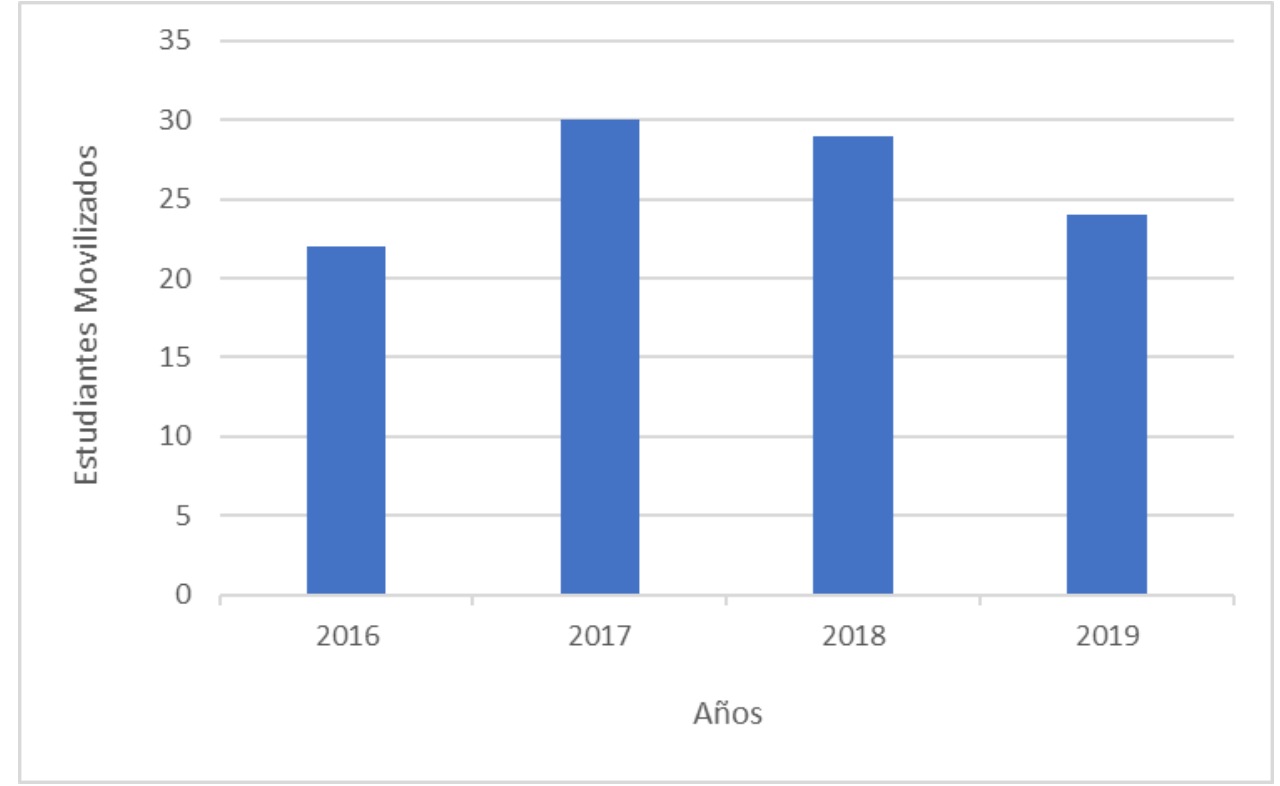

Fuente: Elaboración propia, 2019.

\subsection{Competencias psicosociales emprendedoras}

En este apartado se encuentra el análisis conceptual del término "competencias". Este es extenso en la literatura y, en sus principios, se encontraba estrechamente relacionado con la psicología organizacional (Boyatzis, 1982; Hamel y Prahalad, 1995; Le Boterf, 2001; McClelland, 1973; Spencer y Spencer, 1993; Tejada y Navío, 2005; Woodrufe, 1993). En este último tiempo, el concepto de competencia ha migrado hacia el área de la educación superior. 
Las acepciones son múltiples y variadas según el marco teórico que se utilice. En el presente trabajo se define a la competencia como un saber hacer complejo, para el cual se ponen en juego conocimientos, habilidades y actitudes de distinto tipo (Camargo y Pardo, 2008; Yaniz y Villardón, 2006). De acuerdo con Gutiérrez (2005), el concepto de competencia engloba cinco funciones: (1) cognitiva, que involucra adquirir y usar conocimiento aplicable a la vida real; (2) técnica, que implica el uso de habilidades procedimentales; (3) integradora, con la que se busca relacionar conocimiento básico con aplicado; (4) relacional, a través de una comunicación asertiva, y (5) afectivo- moral, mediante el respeto ante una persona o situación.

En cuanto a las competencias psicosociales emprendedoras, es posible definirlas como las características de la personalidad que se manifiestan en la forma de pensar y actuar vinculadas con la búsqueda y el aprovechamiento de las oportunidades (Carlos Ornelas, Contreras, Silva y Liquidano Rodríguez, 2015). En este sentido, se entiende el término "emprender" en su definición humana y social, y no únicamente ligada al desarrollo económico- comercial (Martínez y Carmona, 2009; Martínez, 2009; Sánchez Caggiano y Hernández, 2011; Sobrado y Fernández Rey, 2010; Trejo López, 2015). Dichas competencias pueden ser innatas o adquiridas (Duran Aponte, 2013), y se relacionan a una actitud optimista, proactiva, persistente y creativa. Así también, la autoeficacia, la capacidad de liderazgo, la resiliencia, las estrategias de afrontamiento, el compromiso, la asunción de riesgos, entre otros son elementos constitutivos de las competencias emprendedoras (López, Vázquez y Montes, 2010; Martínez y Carmona, 2009; Molero, Recio y Cuadrado, 2010; Ortiz, Moncayo y Riaño, 2010; Pino y Aguilar, 2013; Rompato, Silva Peralta y Zucarelli, 2018, Villa y Poblete, 2008).

\section{Metodología}

\subsection{Enfoque}

Se trata de una investigación de metodología cualitativa, diseño fenomenológico y enfoque etnometodológico, de alcance descriptivo. La elección de la metodología seleccionada resulta adecuada para los objetivos propuestos, dado que se tiene como eje la orientación hacia la acción humana y la subjetividad, en donde se destacan a los individuos y el entendimiento que ellos hacen de sus vidas y el mundo que los rodea (Mejía Navarrete, 2002). En este caso, se trató de conocer las experiencias en movilidad y los desafíos vividos 
que el grupo estudiantil declaró transitar, centrándose en la subjetividad del grupo y sin intentar cuantificar los resultados.

La elección de un diseño fenomenológico responde a su propio objetivo: el estudio de fenómenos sociales desde la perspectiva de los actores. El enfoque etnometodológico resulta adecuado por cuanto se centra en el "cómo" de la realidad social, tiene como sujeto de estudio empírico actividades y circunstancias prácticas, y pone como eje la cotidianeidad del sujeto (Urbano Gil, 2007). Tanto la metodología, como el diseño y el enfoque seleccionado permiten realizar una inmersión en la experiencia de movilidad internacional desde la perspectiva del estudiante de grado.

\subsection{Población y muestra del estudio}

La población del presente estudio considera a todo el grupo estudiantil de grado de la UNMDP que hubiera realizado una experiencia en movilidad internacional en los años 2016, 2017 o 2018. Esta es de 81 estudiantes, distribuidos heterogéneamente entre los programas de grado y posgrado que ofrece la universidad. La muestra fue de 36 estudiantes de grado, seleccionados según muestreo intencional. Como criterio de inclusión, se intentó mantener una distribución lo más homogénea posible entre programas de movilidad, y considerar tiempo y universidad de destino. La selección de dichos criterios responde a la necesidad de considerar las diferencias idiosincráticas entre América Latina y Europa.

El grupo estudiantil fue contactado mediante la base de datos del área de Relaciones Internacionales de la UNMDP e invitados a realizar una entrevista de carácter voluntario a través de la firma de un consentimiento informado, en el cual también se estableció el acuerdo de confidencialidad del grupo participante.

De una muestra de 36 individuos, 10 fueron estudiantes hombres y 26 estudiantes mujeres. Asimismo, 25 individuos han realizado estancias en América Latina, su mayoría en Brasil, pero también con experiencias en Uruguay, Paraguay, Chile y México, y 11 han realizado su movilidad en Europa, principalmente en Alemania o Francia. De 36 estudiantes, 23 han realizado experiencias en movilidad internacional en los años 2016, 2017 o 2018 y los restantes 13 , además de realizar dicha experiencia, se han desempeñado como tutores de movilidad estudiantil ${ }^{6}$. La inmensa mayoría realizó estancias cuatrimestrales en la

\footnotetext{
6 Se define como tutor de movilidad estudiantil a un estudiante que, luego de haber realizado su experiencia en movilidad internacional, recibe y acompaña a estudiante extranjeros en la propia IES.
} 
universidad de destino, a excepción de un sujeto, quien lleva a cabo una estancia de un mes, denominada "estancia corta"7.

Los encuentros con el grupo estudiantil fueron llevados a cabo entre los meses de noviembre y diciembre del año 2018, en diversas unidades académicas de la UNMDP, en articulación con el área de Relaciones Internacionales. Por último, es importante destacar que el personal de dicha área se desempeñó a modo de informantes claves, por cuanto proveyó información valiosa sobre los distintos programas de internacionalización de la Universidad.

\subsection{Técnicas de recolección de datos}

La estrategia utilizada fue la de estudio de caso y el instrumento entrevistas semiestructuradas. Estas últimas consisten en diálogos que quienes investigan mantienen con diversas personas a través de ejes temáticos de interés, que pueden verse influenciados según cada experiencia particular, pero que a nivel general logran fluir gracias al rapport establecido previamente con las personas.

Las entrevistas versaron principalmente sobre cuatro bloques fundamentales: datos socio demográficos de cada participante, lo cuales incluyeron nombre, edad, país de destino al realizar la movilidad y tipo de movilidad; pre-movilidad, en donde se indagó todo aquello referido a la gestión previa al momento de realizar la movilidad; movilidad, en donde se consideraron principalmente sus aspectos psicosociales, tales como socialización y adaptación una vez llegados a destino, las actividades realizadas, facilitadores y obstaculizadores de la movilidad; por último, a través de un bloque post movilidad, se indagaron los cambios auto-percibidos fruto de dicha experiencia.

Es importante destacar que tanto la metodología cualitativa y el instrumento de entrevistas semi-estructuradas han sido probados y seleccionados para llevar a cabo análisis correspondientes a la internacionalización de la educación superior (Hernández, 2008; Villalón, 2017).

\subsection{Procesamiento de análisis}

Una vez recogidos los datos se procedió a su desgrabación y posterior carga en el programa Atlas.ti en su versión 7.5.4 para su procesamiento y análisis. Este fue del orden descriptivo, organizado en cuatro fases secuenciales: Durante una primera fase, se realizó

\footnotetext{
7 Son denominadas "estancias cortas" aquellas que tienen una duración de entre 15 y 45 días, aproximadamente.
} 
una lectura superficial de las entrevistas que permitiese comenzar a responder nuestra primera pregunta de investigación: ¿qué tipos de desafíos viven estudiantes de grado que deciden realizar una experiencia de movilidad internacional? Así entonces, se codificaron de manera abierta, o en vivo, todas las citas que hicieran alusión a los desafíos vividos, fueran estos pre movilidad, en el momento de la movilidad y/o post movilidad. Esta instancia sirvió de insumo para la segunda fase, en la cual se llevó a cabo un análisis de mayor profundidad de los desafíos, hecho que posibilitó crear las categorías aquí analizadas: desafíos burocráticos, desafíos culturales, desafíos idiomáticos y desafíos económicos. En esta instancia, también se crearon categorías para diferenciar las movilidades cuyas universidades de destino fueron europeas y latinoamericanas. Finalmente, las citas y categorías de desafíos fueron visualizados y analizados mediante redes, lo que permitió no solo tener una caracterización de cada tipo de desafío, sino dar lugar a la tercera fase, en donde se las interpretaron.

Una vez finalizada la interpretación de los desafíos vividos, se realizó una cuarta fase para dar respuesta a nuestra segunda pregunta de investigación: ¿qué tipo de competencias psicosociales emprendedoras desarrolla el estudiantado que lleva a cabo una movilidad internacional? Esta fase constó de un análisis posterior de los desafíos vividos considerando la bibliografía sobre competencias psicosociales emprendedoras. En ella se buscó atender las competencias de mayor relevancia y repitencia, y posteriormente, re analizar el discurso del estudiantado con base en estas. Así, de un aproximado de veinte competencias relevantes, de acuerdo con la bibliografía fueron encontrados fuertes puntos en común entre cinco de ellas y el discurso de los entrevistados. Estas son: apertura mental hacia nuevas experiencias, autoconocimiento, autonomía, capacidad resolutiva y mirada crítica e integral. A continuación, se presenta en la figura 2 un cuadro sinóptico, a modo de resumen, del procesamiento de análisis. 
Figura 2

Fases del procesamiento de análisis de la información, UNMDP-Argentina, 2016-2019.

Luego de desgrabación y posterior carga en Atlas.ti
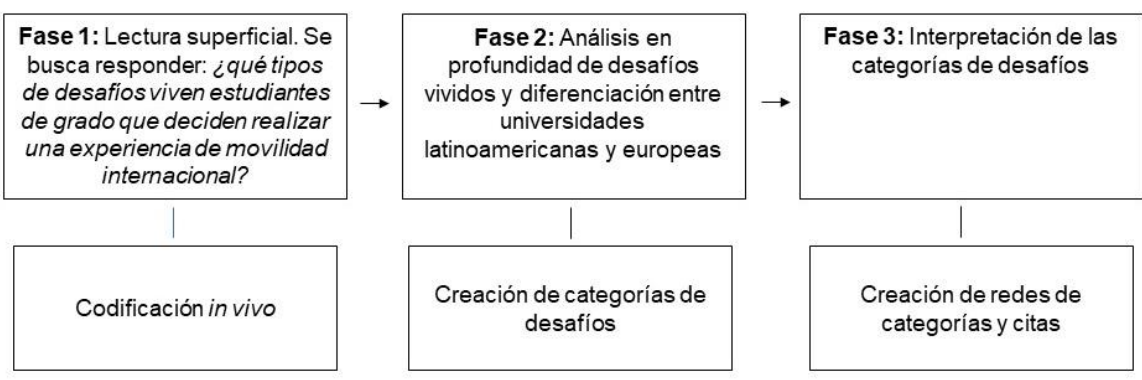

Fase 4: Análisis ex post facto. Se busca responder: ¿qué tipo de competencias psicosociales emprendedoras desarrollael estudiantado que lleva a cabo una movilidad internacional?

Fuente: Elaboración propia, 2019.

\section{Resultados}

Resulta posible organizar los desafíos vividos de acuerdo con cuatro tipologías: cultural, idiomático, burocrático y económico. Estos desafíos mantienen un correlato entre ellos. Una mención aparte merece la cuestión académica que, de acuerdo con la bibliografía consultada, suele presentarse como una problemática y en este caso no lo fue.

\subsection{Desafíos culturales}

Estos desafíos han sido definidos como todo aquello que devenga de los usos y costumbres de la sociedad receptora que pudiese ser percibido o sentido como núcleo problemático para estudiantes. Curiosamente, se ha encontrado que dichos desafíos son percibidos en igual magnitud para movilidades dentro de América Latina y Europa. Así también, son las mujeres estudiantes quienes mayormente hacen alusión a dicho desafío.

Es posible mencionar desafíos culturales relacionados con la percepción de seguridad que se tenga de la ciudad receptora, con la organización social y propios de las relaciones sociales que se establecen.

En cuanto a la percepción de seguridad, se destaca la inseguridad que, principalmente sienten las mujeres en la ciudad receptora, quienes han mencionado sentir acoso callejero, hecho que les genera una profunda incomodidad.

Al hablar de organización social se hace referencia a la comprensión de los distintos usos y costumbres del país receptor, principalmente en lo que refiere a instituciones y horarios. El estudiantado argentino suele desconocer las costumbres del país de recepción, 
por ende, al querer utilizar instituciones tales como farmacias, hospitales o bancos encuentran una lógica horaria completamente distinta. De modo que, al momento de requerir de los servicios de dichas instituciones sufren grandes complicaciones dado que no saben realmente utilizarlas. Entre los ejemplos mencionados las y los estudiantes entrevistados declaran que las guardias de los hospitales funcionan con otra lógica a la argentina y las farmacias cierran los domingos, sin mantener una de turno, como es costumbre en nuestro país. En lo que respecta a instituciones bancarias, las transferencias monetarias se desarrollan con mayor lentitud, lo que conlleva que se organicen económicamente de una forma distinta a la que finalmente van a poder poner en práctica, hecho que puede convertirse en un problema. Al indagar sobre aquellos cambios culturales que mayor incidencia habían tenido en su movilidad, un estudiante comenta:

Que las farmacias estaban cerradas los domingos, que los hospitales se manejaban de otra manera, si o si con turnos, como no había guardias, yo me saqué una muela y tenía que ir un domingo y no había nada, después bueno cuando me tenía ya que volver me habían dicho que tenía que dejar la llave del departamento, como cinco días antes que esté mi vuelo y en realidad yo estaba por contrato hasta el primero de marzo y en la facultad me decían "no, no vos tenés que entregar la llave tal día y me quedé igual porque hable con el encargado del edificio y me dejó quedarme, y después lo que es devolver la plata eso también, el depósito, te lo devuelven después tres o cuatro meses más tarde y te descuentan un montón con la transferencia (E15).

Para finalizar, y en correspondencia con las relaciones sociales que se generan en una movilidad, el grupo estudiantil ha declarado que las formas en las que se comienza un dialogo (más allá de las fronteras idiomáticas) suele ser percibido como un desafío. En general, se desconocen las formas de aproximarse a nuevos compañeros, dado que aquellos necesitan de un largo periodo de tiempo para sentirse íntimos, mientras que el estudiantado argentino afirma necesitar de menor cantidad de tiempo. Esto lleva a afirmar que no tienen con quien sentirse cercanos. En otras ocasiones, se ha encontrado que la comunidad de la universidad receptora simplemente no presenta interés en dialogar con ellos, por lo que el estudiantado argentino decide establecer relaciones entre sí o, en el caso de una movilidad hacia Europa, el estudiantado latinoamericano termina por conformar un grupo endogámico. Esta situación es percibida como problemática. Los y las estudiantes 
afirman que, aunque hayan vivido una buena experiencia a nivel general, no son capaces de vivir un real intercambio cultural.

\subsection{Desafíos lingüísticos}

El idioma ha sido definido como uno de los más grandes desafíos que todo estudiante que realice una movilidad internacional vive, tanto en Europa como en América Latina, específicamente en Brasil. Las mujeres han declarado mayores dificultades percibidas que los hombres, mientras que estos últimos afirman lograr desempeñarse satisfactoriamente con el nivel del idioma que llevaban consigo. En síntesis, se ha encontrado que, pese a tener un buen conocimiento del idioma, al momento de realizar la movilidad el grupo estudiantil comprende las diferencias entre aprender un idioma en un entorno específico para ese fin y vivirlo cotidianamente. La magnitud de este desafío decrece cualitativamente con el correr del tiempo.

En un primer momento, declaran sentirse completamente ajenos a su nueva realidad dado que, pese a tener conocimiento del idioma de destino, no logran comprender cuestiones básicas como cartelería en la calle o instrucciones para llevar a cabo lo que será su primera actividad: realizar trámites. Esta situación se magnifica en estudiantes que también trabajan, ya que tienen que ser capaces de resolver en poco tiempo situaciones de gran relevancia, tales como abrir una cuenta bancaria o entender el contenido de su trabajo. El principal problema radica en que no manejan lenguaje técnico para estas actividades y lo adquieren recién después de dicha situación. La solución momentánea que encuentran es utilizar el idioma inglés como un idioma "puente" entre el español y el idioma de destino. Una entrevistada nos relata:

Al principio con el idioma, o sea si bien la gente habla en inglés y uno puede ir a pedir las cosas en inglés el hecho que todos los carteles estaban en un idioma que no entendía, al principio te sentís como medio perdida, después yo trabajé en una fábrica que era empaquetando libros y yo ahí cuando entre era en abril y no sabía casi nada del idioma, entonces yo ahí con mis compañeros que no sabían inglés y yo que no sabía alemán era como que nos comunicábamos con señas, en principio era medio complicado llegar a hacer lo que tenía que a hacer, pero la verdad que buena predisposición de los dos lado y entonces de a poquito me fui integrando y lo pude sortear $(\ldots)(E 3)$. 
Una vez que logran sortear esa situación sucede una similar en complejidad, que es comenzar a cursar. Se ha encontrado que las primeras clases o cursos resultan particularmente complejos porque, pese a la voluntad del grupo de docentes, en general, al estudiante le resulta complejo comprender su contenido. Aun así, siempre rescatan la voluntad de sus nuevos compañeros por ayudarlos en dicha situación. La entrevistada 10 nos comenta:

El idioma, sobre todo en los primeros cursos, si bien los profesores entienden ellos siguen a su ritmo y me costó porque la primera semana no había conocido a nadie, pero todos eran muy amables y me ayudaron. Al principio pensaba que no iba a entender nada, después los mismos chicos franceses me daban los apuntes (E10).

Es recién finalizando la movilidad que el estudiantado es capaz de sentirse a gusto con la forma en que se desenvuelve lingüísticamente, puede comprender las clases o cursos y mejorar su comunicación social, ya sea para comunicarse con compañeros o en momentos de ocio.

\subsection{Desafíos burocráticos}

Aunque toda forma de desafío burocrático deviene de obligaciones propias del intercambio, la burocracia se expresa en trámites que adquieren diferentes formas, de acuerdo si son dentro de las IES o fuera de ellas. El grupo estudiantil entrevistado declara diferencias cuantitativas para los casos latinoamericano y europeo cuando se trata de trámites dentro de las IES, y diferencias cualitativas cuando estos son por fuera de las IES en Europa. Mujeres y hombres por igual han sido parte de estos desafíos burocráticos.

Por una parte, se encuentran las diligencias hacia el interior de las IES, que son obligatorias como parte del intercambio, y responden principalmente a la necesidad de proveer información personal necesaria para la universidad de destino, la organización de las cursadas y las sedes en donde se estas se llevarán a cabo, entre otras cuestiones. Estos trámites se comienzan en la universidad emisora y finalizan la primera semana del intercambio en la universidad receptora. Las y los estudiantes declaran que estos no son tan complejos en sí, sino que la mayor dificultad radica una vez que llegan a la universidad receptora. Esto se da por dos situaciones: la dificultad lingüística antes mencionada y la propia burocracia de las IES, que se traduce en movilizarse entre distintas sedes, contar con poco tiempo para realizar los trámites, no encontrar los cursos o materias que originalmente 
el estudiante pensó realizar, entre otras cuestiones. Estos desafíos son cuantitativamente mayores en Latinoamérica, aunque afirman que, tanto para esta región como para la europea, la burocracia puede ser superada. Aun así, es importante destacar la marcada carga emocional que conllevan, la cual se traduce en mal estar o estrés. Al preguntarle a una entrevistada cuales consideraba que habían sido sus mayores desafíos nos responde:

Hacer los papeles, eso sí, eso sí fue un tema porque teníamos que presentar algunos papeles y para ir allá, había que ir muy muy lejos a hacer los papeles. Así que eso fue, a parte que estábamos medios apurados porque teníamos una fecha, yo llegué un poco más tarde que el resto así que estaba súper, súper estresada con ese tema, si, ahora que me acuerdo sí (E12).

Por otra parte, el estudiantado lleva a cabo otro conjunto de trámites que, aunque forman parte del intercambio, se realizan por fuera de la IES y algunos de ellos son optativos. Entre estos trámites se destaca cambiar de número de celular a uno del país receptor, abrir una cuenta bancaria y hacer el cambio de domicilio. Estos trámites son comprendidos como altamente burocráticos en países europeos, principalmente Alemania o Francia, donde la rigurosidad para confirmar datos es muy alta. Principalmente se ha encontrado que se presentan serias dificultades para poder llevar a cabo el cambio de domicilio. Este trámite, declaran, es altamente burocrático dado que los pasos a seguir son múltiples, complejos y extensos en el tiempo. Un estudiante complementa indicando las dificultades burocráticas para realizar un cambio de domicilio:

Y a veces muchos trámites allá, tal vez, eran ciertos trámites tal vez que... la burocracia... la burocracia es peor que acá, me acuerdo un día que cuando me mudé tuve que cambiar el domicilio. Para cambiar el domicilio de la línea telefónica me tuve que meter por internet, poner el nuevo domicilio, una vez completado eso, me mandaron al nuevo domicilio una carta, con un pin de siete dígitos aleatorios y cuando yo recibía eso, tenía que llamar a un teléfono, que me atendía una computadora, ingresar eso y después de ahí se hacía efectivo el nuevo domicilio. Está bien que acá [ en Argentina] vos decís 'yo vivo en el Vaticano' y vivís en el Vaticano. Es una declaración jurada, vos sos el responsable, allá un mes te lleva hacer un cambio de domicilio (E21). 
No obstante, es posible afirmar que todo aquel que esté realizando una movilidad se encuentra en la misma situación, o recientemente han terminado de realizar dichos tramites. Por tanto, pese a lo complejo que es se encuentra información y lazos de contención entre compañeros, hecho que se traduce en el éxito de su cometido.

\subsection{Desafíos económicos}

Aunque no ha sido un común denominador, es importante destacar que para parte del estudiantado la cuestión económica fue todo un desafío. Los datos indican que esta situación tiende a magnificarse para el caso latinoamericano. Por cierto, una vez más son las estudiantes mujeres quienes mayormente declaran haber vivido dicho desafío.

Su desarrollo se debe a varios factores. El primero se origina en la inestabilidad económica argentina, que resulta en una dificultad cambiaria al momento de afrontar los gastos. El segundo factor deviene del valor de las becas de ayuda económica obtenidas, que el grupo estudiantil declara insuficientes para mantenerse, por lo que inevitablemente necesitan de ayuda familiar. El último factor se encuentra estrechamente relacionado con los desafíos culturales y burocráticos recientemente descriptos. Debido al desconocimiento del sistema bancario del país receptor, muchas veces, se enfrentan a problemas para abrir una cuenta bancaria o usar su tarjeta de débito o crédito, lo que, eventualmente se traduce en un problema económico dado que se encuentran con un faltante de liquidez para gastos diarios o para el pago del alquiler. La entrevistada 30 comenta:

Lo difícil fue gestionar el dinero porque fue la suba del dólar, la beca es de los dos gobiernos, además al hacer los trámites a último momento, allá se nos complicó (E30). Otra entrevistada complementa:

Cuando me fui en octubre subió el dólar y la diferencia de moneda fue bastante. La universidad de acá te da poca plata, tenés que poner plata de tu bolsillo (E32).

En la inmensa mayoría de los casos, los desafíos económicos son superados con el esfuerzo de familiares y el esfuerzo personal de una mejor administración monetaria. En el caso de la falta de liquidez para pagar el alquiler, el estudiantado rescata la actitud comprensiva y paciente de los dueños del inmueble alquilado, quienes esperan hasta que la situación mejore. La entrevistada 22 dice al respecto:

Tuve un problema con la tarjeta, las primeras tres semanas no me andaba, yo estaba como loca. Además, tampoco tenía celular así que hacía los trámites por teléfono en 
casa, me caminaba 20 cuadras y probaba la tarjeta un día hice como cinco viajes, con cuarenta grados de sensación térmica y a pleno sol. Después a los quince días llegó un argentino, un cordobés, y mis papás me depositaron para que pague el alquiler por lo menos. La chica no tenía problema, porque sabía del problema con la tarjeta, pero yo me sentía mal, recién llegada y ya le debía el alquiler (E22).

\subsection{Desafíos académicos}

Tanto para el caso latinoamericano como europeo, en general se encuentra que el grupo estudiantil cree que la universidad de origen proporciona sólidos conocimientos en su carrera, por lo que no encuentran mayores desafíos al momento de cumplir con sus obligaciones académicas en su nueva universidad. Aun así, perciben como positiva la nueva experiencia académica en tanto logran aprender diversos conocimientos, más allá del académico, asistir a cursos o realizar actividades que forman parte de sus respectivas incumbencias profesionales, pero que en la universidad de origen no se encuentran. En simples palabras, no se encuentra una dificultad, sino una complementariedad a nivel académico.

\section{Desarrollo de competencias psicosociales emprendedoras}

A continuación, se presentará un análisis de las competencias psicosociales desarrolladas como consecuencia de los desafíos vividos durante las diversas movilidades internacionales y se hace especial hincapié en la forma en que competencias y desafíos se relacionan entre sí. Se encontraron doce competencias psicosociales emprendedoras. La apertura mental hacia nuevas experiencias, el autoconocimiento, la autonomía, la capacidad resolutiva y la mirada crítica e integral son las competencias de mayor repitencia, mientras que el desafío cultural es el de mayor asociación a las competencias antes nombradas.

\subsection{Apertura mental hacia nuevas experiencias}

La apertura mental hacia nuevas experiencias supone un ejercicio básico de mantener una actitud receptiva ante nuevos desafíos. El grupo entrevistado afirma que el hecho de vivir una experiencia de movilidad internacional proporciona este tipo de actitud.

Mientras que previo a la movilidad muchos se consideraban vergonzosos, prejuiciosos o cerrados en su propio pensamiento, el desafío cultural que supone una movilidad logra cambiar la forma de ver su propia realidad y la ajena. El estudiantado sufre una ruptura 
paradigmática que tiene incidencia en múltiples aspectos de su vida, aunque se destacan el ámbito personal y académico/ profesional. En lo que refiere al ámbito personal, se ha encontrado que debido a esta apertura mental el estudiantado modifica las consideraciones que antes tenían sobre su propio país, familia y amigos, mientras que la apertura mental en el ámbito académico/ profesional les proporciona el reconocimiento de diversas incumbencias profesionales y la curiosidad por llevarlas adelante. También, es de destacar la consideración que adquieren sobre la internacionalización. Mientras muchos de ellos comenzaron el proceso de movilidad como una curiosidad o para conocer otra cultura, cuando vuelven adquieren una mayor comprensión de las posibilidades que supone concebir su propia formación desde una mirada internacional.

\subsection{Autoconocimiento}

El autoconocimiento supone el reconocimiento de los rasgos característicos de la estructura de personalidad subyacente (Vogt y Colvin, 2005), lo que involucra elementos tales como emociones, actitudes, comportamientos, metas, rasgos, recuerdos autobiográficos, entre otros (Tenney, Vazire y Mehl, 2013).

La movilidad supone un quiebre con la rutina en su ciudad de origen, lo que genera tiempo y espacio suficiente para que adquieran una actitud reflexiva sobre su propia vida, que los lleva a conocerse con mayor detenimiento. Por una parte, este nuevo conocimiento sirve para reafirmar metas, actitudes, formas de pensamiento y también para erradicar viejas formas que, a la luz de esta nueva experiencia, carecen de sentido. En el desarrollo de esta competencia resultan claves los desafíos culturales y burocráticos vividos antes nombrados. Aunque previo a la movilidad estos desafíos parecían impensados, su vivencia genera que los y las estudiantes se replanteen su nueva conducta ante las responsabilidades y sientan que esa parte de sí siempre había estado, simplemente la "comodidad cotidiana" impedía que saliera a la luz.

Por otra parte, la nueva experiencia académica, propia de la movilidad, conlleva un autoconocimiento de las metas académico- profesionales. Es a partir de esta experiencia que el estudiantado confirma el camino de su vida académica o reconoce nuevas necesidades antes ocultas, hecho que se traduce en una forma de autoconocimiento personal y profesional. 


\subsection{Autonomía}

La autonomía refleja la posibilidad de decidir y actuar por sí mismo, con independencia del deseo o accionar de un tercero.

En el caso del grupo aquí analizado, la autonomía forma parte de todo un entramado personal e individual que se reconoce como "madurar". Dos son los momentos claves a partir de los cuales afirman sentirse individuos más autónomos. El primero se relaciona con el desafío cultural de llegar a la universidad receptora y no conocer a nadie, ni tener una persona cercana de confianza. Ese sentido de soledad los y las obliga a convertirse en personas autónomas e independientes, a decidir por sí mismas, en principio por obligación y finalmente por convicción.

El segundo momento se relaciona con los desafíos económicos. Si bien no todos declararon vivir tal desafío, aquellos que sí lo han hecho entienden que gracias a este han ganado nuevas capacidades de organización monetaria que se traducen en mayor autonomía, ya que no dependen del consejo o administración de un tercero para tal fin.

\subsection{Capacidad resolutiva}

Al hablar de capacidad resolutiva se hace referencia a los cambios cualitativos y cuantitativos que una persona evidencia al momento de exponerse ante un desafío. En términos operativos, supone reconocer si el sujeto resuelve más y mejor diversas situaciones. En los casos analizados, la capacidad resolutiva se encuentra estrechamente relacionada con la autonomía, dado que solo a partir de sentirse autónomos pueden mejorar dicha capacidad.

Debido a los desafíos culturales, burocráticos y lingüísticos vividos, los y las estudiantes afirman que su capacidad resolutiva ha mejorado cualitativa y cuantitativamente. No solamente resuelven cuestiones que antes parecían impensadas, sino que lo hacen con mayor comodidad. Dicha capacidad se vivencia principalmente en el ámbito burocrático y cultural. En lo que respecta al primero, se ha encontrado que la obligación de tomar decisiones importantes en solitario conlleva eventualmente a mejorar sus capacidades resolutivas, porque descubren que efectivamente pueden hacerlo de manera satisfactoria.

Sobre el ámbito cultural, el grupo estudiantil afirma que tener que relacionarse pese a su incomodidad, vergüenza o desconocimiento de usos y costumbres básicos los obliga a "sacarse el miedo" de acercarse e intentar establecer vínculos. 
Tanto al ámbito burocrático como al cultural hay que sumarle un gran componente: el lingüístico. El mayor desafío y miedo resulta de la obligación de resolver toda situación que pudiese surgir en un idioma diferente al nativo. Al reconocer que, con mayores o menores complicaciones pueden llevar a cabo dicha acción, reconocen su propia capacidad resolutiva y se encaminan en un actuar consecuente con ella.

\subsection{Mirada crítica e integral}

La capacidad de desarrollar una mirada crítica e integral hace referencia a un continuo cuestionamiento del mundo que nos rodea, lo que promulga un análisis sistémico de él. Para el grupo estudiantil, esto significa mantener una mirada crítica e integral tanto de su propia cultura y, particularmente, de sus propias IES, como de la cultura e IES receptora. Es decir, el cuestionamiento surge en una doble vía.

En lo que respecta a la mirada crítica e integral sobre la cultura, se encuentra que posterior a una movilidad internacional el grupo estudiantil logra obtener una mirada más global sobre la cultura y valorar tanto la propia como la ajena. Esta valoración no siempre es positiva, sino que los y las estudiantes son capaces de reconocer aquello positivo y negativo, y mantener una actitud proactiva. También logran comprender el sentido subyacente en actitudes o formas de ser, ya que logran encuadrarlas dentro de la cultura que les dan sentido.

Con respecto a su propia IES, se ha encontrado que el grupo estudiantil logra analizarla desde una perspectiva crítica y considera no solo diferencias curriculares entre la IES emisora y la IES receptora, sino también diferencias en cuanto a recursos materiales y humanos. Esto significa que no solo se desarrolla una mirada crítica de la institución, sino que se fomenta una mirada integral, a partir de la cual logran comprender que un desarrollo académico fructífero y armonioso conlleva múltiples elementos que exceden la malla curricular.

\subsection{Otras competencias}

Las competencias previamente señaladas responden a patrones sostenidos encontrados en la muestra entrevistada. Pese a esto, resulta interesante destacar que no han sido las únicas halladas, sino que en menor medida se puede hablar de la asunción de riesgos, confianza, estrategias de afrontamiento, optimismo, proactividad, seguridad y tolerancia localizados en el estudiantado. 
Estas competencias están estrechamente relacionadas con las previamente desarrolladas, y responden a un mismo patrón de comportamiento en cuanto su desarrollo se debe al traspaso exitoso de los múltiples desafíos a los que se enfrenta un estudiante de grado que decide realizar una movilidad internacional.

\section{Discusión de resultados}

Los datos analizados permiten afirmar que el estudiantado de grado de la UNMDP, que ha realizado una experiencia de movilidad internacional, se somete a cuatro grandes desafíos. En sentido general, estos desafíos responden principalmente a desconocimiento de los usos y costumbres de una cultura ajena que implica una batería de elementos constitutivos que van desde la forma de relacionarse hasta la forma de realizar un trámite.

El primero de ellos, y de gran incidencia futura, es el desafío cultural. Este se vislumbra en tres esferas: macro- social, referido principalmente a la percepción de seguridad/ inseguridad que de la ciudad receptora se tenga, institucional, principalmente sanitaria y bancaria de la ciudad receptora, y micro social, debido a las relaciones sociales que se generan fruto del intercambio.

El segundo desafío que transita el estudiantado se refiere al idioma, hecho que es notorio en países como Francia y Alemania, en Europa, y Brasil, en América Latina. En este sentido, el principal desafío es el lenguaje técnico, referido a señalética en el ámbito público o palabras propias del ámbito de la salud, educación o bancario, instituciones a las que el estudiantado se aproxima para realizar sus primeros trámites.

El tercer desafío refiere, justamente, a la burocracia, comúnmente vivida a través de dichas diligencias. Esta burocracia se vive tanto dentro de las IES como fuera de ellas. Mientras que en el primer caso refiere a acciones como darse de alta en la nueva IES, seleccionar cursadas, conocer sedes, etc., en el segundo caso hace referencia a cambiar el domicilio, abrir cuentas bancarias, cambiar de número telefónico, etc. La burocracia dentro de las IES es percibida como mayor en países latinoamericanos, y la burocracia fuera de las IES es percibida de mayor complejidad dentro de países europeos.

El último desafío es el económico. Este se desarrolla tanto por la actualidad económica argentina, sometida a una fuerte depreciación de su moneda; por un sistema de becas considerado insuficiente para responder a necesidades básicas como transporte, alojamiento y alimentación; y por falta de conocimiento del sistema bancario del país de recepción, hecho que hace que el grupo estudiantil enfrente, en ciertas ocasiones, problemas de liquidez. 
Es interesante mencionar que la cuestión académica no fue percibida como un desafío, debido a que el estudiantado se percibe a sí mismo como capaz de aprehender el contenido, más bien encuentra una complementariedad entre la IES emisora y la IES receptora.

A su vez, el análisis de competencias realizado demuestra que los desafíos transitados no son en vano y que, pese a mejoras que podrían realizarse, el estudiantado logra reconvertirlos en competencias con una marcada implicancia positiva en su vida académica y cotidiana. Las principales competencias psicosociales emprendedoras encontradas son: apertura mental hacia nuevas experiencias, autoconocimiento, autonomía, capacidad resolutiva y mirada crítica e integral. En menor medida, se han encontrado competencias tales como la asunción de riesgos, confianza, estrategias de afrontamiento, optimismo, proactividad, seguridad y tolerancia.

La apertura mental hacia nuevas experiencias se relaciona principalmente con los desafíos culturales que el estudiantado transita, y que conducen a reconsiderar sus características personales y académico profesionales, y mantener una mirada de aceptación a nuevas realidades y oportunidades antes no consideradas. Estrechamente relacionado, se produce un marcado desarrollo del autoconocimiento. Los desafíos culturales y burocráticos vividos les demuestran que son capaces de llevar a cabo sus objetivos de manera que antes desconocían. Este autoconocimiento se desarrolla tanto en el ámbito personal como profesional, potenciando la manera de verse a sí. Por otra parte, el hecho de transitar en soledad la experiencia de movilidad, y por ende, no contar con personas cercana que los ayuden a sortear los problemas propios de los desafíos burocráticos y económicos vividos, obliga al estudiantado a desarrollar su autonomía. A su vez, mientras que, en principio, el grupo estudiantil se ve obligado a buscar soluciones a los desafíos culturales, burocráticos e idiomáticos, eventualmente logra sentirse capaz y a gusto con su accionar, haciendo que la autonomía se complemente con el desarrollo de la capacidad resolutiva. Por último, el grupo estudiantil desarrolla una mirada crítica e integral, no solo de su propia realidad y cultura, sino principalmente de su IES y de la IES receptora. Esta mirada se relaciona con la capacidad de valorar ambas IES y sobre todo de comprender que la excelencia académica no solo tiene que ver con las mallas curriculares, sino también con recursos humanos y materiales.

Las investigaciones relacionadas con la internacionalización de la educación superior no resultan abundantes. Se espera que dicha situación se resuelva a futuro mediante sul desarrollo continuado. De todas formas, es posible encontrar correlatos entre investigaciones 
previas y la presente. Al tomar en cuenta el análisis sobre las experiencias académicas en una movilidad realizado por Santiago Ruiz et al. (2018), se encontrará que todas las experiencias allí descriptas (experiencias en las estrategias didácticas, en la forma de calificar, en la aplicación de los exámenes y en las dinámicas de la vida académica de la institución receptora) son consideradas como desafiantes para el estudiantado en cuestión, independientemente de la valoración positiva o negativa que aquellas tuvieran. Resulta interesante destacar que dicho resultado contradice al encontrado en la presente. Como se ha dejado ver, la experiencia académica, en sentido general, no solo no ha resultado desafiante, si no que no es percibida como dificultosa.

Al adentrarse en un análisis de competencias es posible ver que investigaciones previas analizan la experiencia de estudiantes angloamericanos, que realizan una estadía en universidades mexicanas (Hernández, 2008). La autora encontró un destacado desarrollo de competencias interculturales y competencias lingüísticas que impactan positivamente en la identidad de dichos estudiantes. La mirada crítica e integral que los y las estudiantes de la UNMDP logran adquirir mediante la movilidad se encuentra en estrecha relación con la competencia intercultural descripta en dicha investigación. Es a partir de esta mirada que, además de considerar sistémicamente sus propias realidades, generan empatía con una cultura antes desconocida y logran crecer personalmente, fruto de esta transformación.

Por todo lo anteriormente expuesto, es posible afirmar que las experiencias en movilidad internacional surten un efecto positivo en los estudiantes en múltiples niveles. No solo mejoran al complementar sus experiencias académicas, sino que logran aprender y gestionar nuevos conocimientos, habilidades y actitudes que los acompañarán durante todo su desarrollo individual, académico y profesional. Esta idea se encuentra en consonancia con la realizada por García Palma (2013), quien afirma que la movilidad estudiantil es propuesta como una mejora de la formación profesional, la movilización de saberes y la estructuración de redes de intercambio. A su vez, es posible retomar las palabras de Santiago Ruiz et al. (2018), y afirmar que la experiencia de movilidad internacional supuso un re aprendizaje a través de la experiencia, lo cual, acerca al estudiantado a nuevas maneras de comprender el mundo y sus necesidades; es decir, los ayuda a conformarse como "ciudadanos del mundo", con el sentido de la responsabilidad social y competencias necesarias para desenvolverse efectivamente. 


\section{Conclusiones}

El presente trabajo adscribe a la perspectiva de competencias de la educación superior. Esta perspectiva comprende que solo reorganizando mallas curriculares, redefiniendo campos disciplinares y desarrollando competencias adecuadas en los estudiantes es que se podrán emprender soluciones para este mundo globalizado. Así también, propone nuevos caminos para re conceptualizar la actividad de internacionalización, muchas veces mal interpretada o subestimada.

Las autoras definen a las competencias como un saber hacer complejo que incluye conocimientos, habilidades y actitudes de distinto tipo. La internacionalización de la educación superior en la UNMDP- Argentina supone un camino para adquirir este saber hacer complejo y de alto impacto en el mundo educacional y laboral; es así que debiera configurarse como una actividad de gran importancia.

A su vez, de este estudio surge la necesidad de continuar indagando sobre la relación entre los procesos de internacionalización y el desarrollo de competencias. Al respecto, Ramírez y Ortega (2018) afirman que no solo se trata de considerar las competencias que se desarrollan como consecuencia de una actividad de movilidad internacional, sino también de analizar aquellos perfiles propensos a realizar este tipo de experiencias. Es por esto que resulta de interés abordar futuras líneas de investigaciones que aboguen por conocer dichos perfiles.

En relación a esto, es importante recordar las palabras de Duran Aponte (2013), quien afirma que las competencias pueden ser tanto innatas como adquiridas. Por tanto, se cree que la UNMDP no solo debería comprender la internacionalización como un proceso de desarrollo de competencias de alto impacto, sino que también debería trabajar sobre su adquisición de manera sinérgica entre todos sus ámbitos: docencia, investigación, extensión y transferencia, llevando a cabo acciones integrales destinadas a la formación de competencias críticas para el desarrollo del estudiantado.

Esta investigación también permitió abrir nuevos caminos para repensar la relación entre la responsabilidad social universitaria (Vallaeys, De la Cruz y Sasia, 2009) y el desarrollo de actividades como la internacionalización. Las nuevas problemáticas sociales (de contaminación, tecnológicas, alimenticias, entre otras) conllevan nuevas formas de pensar soluciones. Las UNMDP no es ajena a tal realidad, por lo que precisa de nuevas estrategias de afrontamiento. Es así que este estudio podría ser de utilidad para que las autoridades universitarias puedan comprender que actividades como la internacionalización 
forman parte de la responsabilidad social universitaria, dado que fomenta una visión del mundo actualizada y coherente con las problemáticas y necesidades actuales en los estudiantes.

En relación a esto, a futuro se espera también recoger datos de manera longitudinal para analizar el sostenimiento en el tiempo de las competencias encontradas y de las implicaciones personales y profesionales en el cuerpo de estudiantes y graduados. De acuerdo con los datos encontrados, sería de importancia sumar la variable de género para estudiar con detenimiento las diferencias encontradas entre hombres y mujeres estudiantes.

Las investigaciones sobre internacionalización de la Educación Superior son relativamente nuevas, más aún, aquellas que tienen por objetivo conocer los factores que motivan a realizar esta actividad. La presente investigación se suma a esta corriente con el espíritu de colaborar con nuevas perspectivas que comprendan a la internacionalización de las IES como una actividad de crecimiento personal, humano y profesional. Hecho que, a su vez, significará mayores oportunidades institucionales, regionales y, por qué no, nacionales. Como bien fue expresado en la introducción, se trata de dar respuesta a un mundo cada vez más complejo, dinámico e impredecible.

Del este modo, se espera que los resultados aquí encontrados hayan permitido al lector conocer la riqueza social y humana que conlleva potenciar la internacionalización en el plano de la educación superior. Igualmente, que pueda servir para el área de Relaciones Internacionales de cualquier universidad en el desarrollo de nuevas estrategias de fomento.

El desarrollo de la investigación no contó con mayores dificultades, aun así, dentro de las limitaciones podría nombrarse la imposibilidad de una distribución homogénea entre los programas, fruto del carácter voluntario de la participación.

\section{Agradecimientos}

Las autoras agradecen a las estudiantes Mónica Martorana, Luciana Casagrande, Evangelina de Hormaechea y Yanina Heguy, quienes han facilitado la recolección de los datos, así como también al staff de Relaciones Internacionales de la UNMDP, que cedieron desinteresadamente su tiempo para la realización de la presente investigación. 


\section{Referencias}

Aguilera de Drelichman, Pilar. (2017). La internacionalización y su influencia en la educación superior. Revista Científica de la Facultad de Filosofía - UNA, 5(2), 1-13. Recuperado de $\quad$ http://www.fil.una.py/investigacion/index files/2018.1/Pilar-Aguilera-deDrelichman.pdf

Alcón, Eva. (2011). La internacionalización de los estudiantes universitarios. La Cuestión Universitaria, (7), 32-39. Recuperado de http://polired.upm.es/index.php/lacuestionuniversitaria/article/view/3354/3496

Arango, Ana María y Acuña, Luis Eduardo. (2018). La internacionalización del currículo y su relación con las condiciones de calidad en los programas académicos de educación superior para la obtención de registro calificado. Revista ObIES, 2, 35-49. Recuperado de https://revistas.udistrital.edu.co/index.php/obies/article/view/12739/13230

Boyatzis, Richard. (1982). The competent manager: A model for effective performance. New York: John Wiley and Sons.

Camargo, Itala y Pardo, Carlos. (2008). Competencias docentes de profesores de pregrado: Diseño y validación de un instrumento de evaluación. Universitas Psychologica, 7(2), 401-455.

Recuperado

en: https://revistas.javeriana.edu.co/index.php/revPsycho/article/view/441

Carlos Ornelas, Carmen Estela; Contreras, Luis; Silva, María de los Ángeles y Liquidano Rodríguez, María del Carmen. (2015). El Espíritu Emprendedor y un factor que influencia su Desarrollo Temprano. Conciencia Tecnológica, (49), 46-51. Recuperado en: https://www.redalyc.org/pdf/944/94438997006.pdf

De Wit, Hans. (1995). Strategies for the internationalization of higher education. $A$ comparative study of Australia, Canada, Europe, and the United States of America. Amsterdam: European Association of International Education (EAIE).

Delgado Márquez, Blanca; Hurtado Torres, Nuria Esther y Bondar, Yaroslava. (2011). La internacionalización en la enseñanza superior: investigación teórica y empírica sobre su influencia en las clasificaciones de las instituciones universitarias. Universities and Knowledge Society Journal, 8(2), 101-122. Recuperado de https://rusc.uoc.edu/rusc/ca/index.php/rusc/article/view/v8n2-delgado-hurtadobondar.html

Delors, Jacques. (1996). Education for tomorrow. Unesco Courier, 49, 6-11.

Didou Aupetit, Sylvie y Gerard, Ettiene. (2009). Fuga de cerebros, movilidad académica y redes científicas. Perspectivas latinoamericanas. México: IESALC- CINVESTAV- IRD.

Durán Aponte, Emilce. (2013). Distinción entre actitud emprendedora y autoeficacia emprendedora: validez y confiabilidad en estudiantes universitarios. Educación y futuro digital, 5(7), 59-69. Recuperado en: https://cesdonbosco.com/documentos/revistaeyfd/EYFD 7.pdf 
Gacel, Jocelyn. (2000). La dimensión internacional de las universidades mexicanas. Educación Superior y Sociedad, 11(1 y 2), 121- 142.

García Palma, Jonathan Jesús. (2013). Movilidad internacional estudiantil y cooperación educativa en el nivel superior de educación. Revista Iberoamericana de Educación, 61(4), 59-76. Recuperado de https://rieoei.org/RIE/issue/view/76

Geldres, Valeska; Vásquez, Fabiola y Ramos, Heidy. (2013). Internacionalización de la educación superior en Chile. Movilidad internacional de estudiantes en la Universidad de La Frontera. Revista Iberoamericana de Ciencia, Tecnología y SociedadCTS, 8(24), 45-62. Recuperado de https://www.redalyc.org/pdf/924/92429917003.pdf

Guido Guido, Elsiana y Guzmán Aguilar, Ana. (2012). Criterios para internacionalizar el currículum universitario. Revista Electrónica Actualidades Investigativas en Educación, 12(1), 1-25. Recuperado de https://revistas.ucr.ac.cr/index.php/aie/article/view/10253

Gutiérrez, Olga. (2005). Educación y entrenamiento basados en el concepto de competencia: implicaciones para la acreditación de programas de Psicología. Revista Mexicana de Psicología, 22, 253-270. Recuperado de http://sociedadmexicanadepsicologia.org/index.php/publicaciones/revista-mexicana-depsicologia

Guy, Haug. (2010). La internacionalización de la educación superior: más allá de la movilidad europea. La Cuestión Universitaria, (6), 20-29. Recuperado en: http://polired.upm.es/index.php/lacuestionuniversitaria/article/view/3392

Hamel, Gary y Prahalad, C.K. (1995). Compitiendo por el futuro: Estrategia crucial para crear los mercados del mañana. Barcelona: Ariel.

Hernández, María del Rosario. (2008). Movilidad estudiantil de norte a sur. Un estudio cualitativo. Guadalajara: Universidad de Guadalajara.

Hernández, Viridiana, Domínguez, Martha, Almaraz, Alan Jesús Leonardo y Escamilla, Marisela Dzul. (2014). Movilidad estudiantil: una maleta llena de recuerdos. EDÄHI Boletín Científico de Ciencias Sociales y Humanidades del ICSHU, 3(5). Recuperado en:

https://repository.uaeh.edu.mx/revistas/index.php/icshu/article/download/936/4152?inlin $\underline{\mathrm{e}=1}$

Jaramillo, Isabel Cristina. (2003). La internacionalización de la Educación Superior y su Dinámica en Colombia. Colombia: Banco Mundial. Oficina Regional para América Latina y el Caribe. Recuperado de http://documents.worldbank.org/curated/en/558071468018838614/pdf/324320LCSHD0 PAPER0SERIES08201Type0LHSD1.pdf

Juárez Salomo, Norma Angélica; Gama Hernández, Gerardo y Cuevas Olascoaga, Miguel Ángel. (2019). Estrategias de internacionalización para la información integral en turismo (Colección Revistas de Divulgación). México D.F.: CONACYT,. Recuperado de http://riaa.uaem.mx/handle/20.500.12055/833 
Karady, Victor. (2006). Movilidad estudiantil y universidades occidentales: pautas de intercambio desigual en el mercado académico europeo, 1880-1939. En Charle, Cristophe, Schriewer, Jurgen y Wagner, Peter (Eds.), Redes intelectuales transnacionales: formas de conocimiento académico y búsqueda de identidades culturales. Barcelona: Ediciones Pomares.

Knight, Jane. (1997). Internationalization of higher education: A conceptual framework. En Jane Knight y Hans De Wit (eds.), Internationalization of higher education in the Asia Pacific countries. Ámsterdam: European Association of International Education (EAIE).

Le Boterf, Guy. (2001). Ingeniería de las competencias. Barcelona: Gestión 2000.

Lechini, Gladys. (2009). Africa and South America (South Africa, Argentina and Brazil) Lessons for South-South Cooperation. África Review, 1(1), 73-86. Recuperado en: https://www.tandfonline.com/doi/abs/10.1080/09744053.2009.10597281 ?journalCode=r afr20

Leeds, Hurwitz. (2017). Competencias interculturales: marco conceptual y operativo. Colombia: Universidad Nacional de Colombia.

López Echeverri, Gloria Helena. (2014). La internacionalización de la educación superior y la formación de ciudadanos del mundo, ciudadanos glocales. Sophia, 10(2), 64-69. Recuperado de https://revistas.ugca.edu.co/index.php/sophia/article/view/256

López, Ángeles; Vázquez, Paula y Montes, Carlos. (2010). Mobbing: antecedentes psicosociales y consecuencias sobre la satisfacción laboral. Revista Latinoamericana de Psicología, 42(2), 215-224. Recuperado en: http://publicaciones.konradlorenz.edu.co/index.php/rlpsi/article/view/474

Martínez, Francisco Miguel y Carmona, Gabriel. (2009). Aproximación al concepto de "competencias emprendedoras": valor social e implicaciones educativas. Revista Iberoamericana sobre Calidad, Eficacia y Cambio en Educación, 7(3) 82-98. Recuperado de https://www.redalyc.org/pdf/551/55114063007.pdf

Martínez, Francisco Miguel. (2009). Programa socioeducativo para el desarrollo de la cultura emprendedora entre los jóvenes. Revista Iberoamericana de Educación, 50(5), 1-13. Recuperado de https://rieoei.org/RIE/article/view/1919

McClelland, David. (1973). Testing for competences rather than for intelligence. American Psychologist, 28(1), 1-14.

Mejía Navarrete, Julio. (2002). Problemas Metodológicos de las Ciencias Sociales en Perú. Universidad Mayor de San Marcos, Lima: Fondo Editorial de la Facultad de Ciencias Sociales.

Molero, Fernando; Recio, Patricia y Cuadrado, Isabel. (2010). Liderazgo transformacional y transaccional: un análisis de la estructura factorial del Multifactor Leardership Questionaire (MLQ). Psicothema, 22(3), 495-501. Recuperado en: https://www.redalyc.org/pdf/727/72714400022.pdf 
Morresi, Silvia; Elías, Silvina y Quartucci, Elisa. (2018). Políticas de Internacionalización de la educación superior: un análisis comparado para América Latina. Gestión de las Personas $y$ Tecnología, 11(31), 39-55. Recuperado en: http://www.revistas.usach.cl/ojs/index.php/revistagpt/article/view/3227

Orantes De Pineda, Blanca Ruth. (2015). Internacionalización de la educación superior. Entorno (47), 57-64. Recuperado de http://biblioteca.utec.edu.sv/entorno/index.php/entorno/article/view/80

Ortiz, Carolina; Moncayo, Carolina y Riaño, Adriana. (2010). Caracterización de las dimensiones del liderazgo transformacional en estudiantes de pre grado de la Universidad Militar Nueva Granada. Revista Educación y Desarrollo Social, 4(2), 60-74. Recuperado en: https://repository.unimilitar.edu.co/handle/10654/18226

Pino, Rebeca y Aguilar, María de los Ángeles. (2013). La inteligencia emocional como una herramienta de la gestión educativa para el liderazgo estudiantil. Cuadernos de Administración, 29(50), 132-141. Recuperado en: http://cuadernosdeadministracion.univalle.edu.co/index.php/cuadernos de administraci on/\%20article\%20/view\%20/49

Pons, Esther Belvis; Pineda Herrero, Pilar y Moreno Andrés, María Victoria. (2007). La participación de los estudiantes universitarios en programas de movilidad: factores y motivos que la determinan. Revista iberoamericana de educación, 42(5), 1-14. Recuperado de https://rieoei.org/RIE/article/view/2397

Ramírez, Argelia y Ortega, Juan Carlos. (2018). ¿Quiénes son los estudiantes que hacen movilidad internacional? El caso de la Universidad Veracruzana. Revista Interamericana de Educación de Adultos, 40(1), 81-110. Recuperado en: http://www.redalyc.org/articulo.oa?id=457556162005

Ramírez, María Mercedes y Montañez, Leidy Yohanna. (2014). Aspectos que interfieren en la movilidad estudiantil. Revista Ciencia y Cuidado, 11(2), 59-73. Recuperado en: https://revistas.ufps.edu.co/index.php/cienciaycuidado/article/view/198

Rodríguez Betanzos, Addy. (2014). Internacionalización curricular en las universidades latinoamericanas. Revista Argentina de Educación Superior, 6(8), 149-168. Recuperado en: https://dialnet.unirioja.es/servlet/articulo?codigo=4753883

Rompato, María Emilia; Silva Peralta, Yamila y Zucarelli, Marianela. (2018). ¿El becario de investigación es un emprendedor universitario? Un análisis exploratorio. Presentado en VIII Congreso Marplatense de Psicología, Universidad Nacional de Mar del Plata, Argentina.

Sánchez, José; Caggianno, Valeria y Hernández, Brizeida. (2011). Competencias emprendedoras en la educación universitaria. International Journal of Development and Educational Psychology, 3(1), 19-28. Recuperado en: https://www.redalyc.org/pdf/3498/349832330001.pdf 
Santiago Ruiz, Pedro Ramón; Zúñiga, Silvia Patricia y Rodríguez, José Félix. (2018). Cruzar fronteras, reaprender en el trayecto... experiencias académicas de los estudiantes que participan en una movilidad estudiantil a nivel internacional. Visión educativa, 12(25), 12-19. Recuperado en: http://iunaes.mx/inicio/wp-content/uploads/2018/04/RevistaVisi\%C3\%B3n-IUNAES-No.-25.pdf\#page=18

Sebastián, Jesús. (2011). Dimensiones y métrica de la internacionalización de las universidades. Universidades, $\quad$ O(51), 3-16. Recuperado en: https://www.udual.org/principal/revista-universidades/

Sobrado, Luis y Fernández Rey, Elena. (2010). Competencias emprendedoras y desarrollo del espíritu empresarial en los centros educativos. Educación XXI, 13(1), 15- 3. Recuperado de http://revistas.uned.es/index.php/educacionXX1/article/view/275

Soderqvist, Minna. (2002). Internationalization and its management at higher-education institutions. A Conceptual, content and discourse analysis (Thesis doctoral). Helsinki School of Economics, Helsinki, Finland. Recuperado de https://aaltodoc.aalto.fi/handle/123456789/11206

Spencer, Lyle y Spencer, Signe. (1993). Competent at work: models for superior performance. New York: John Wiley and Sons.

Tejada, José y Navío, Antonio. (2005). El desarrollo y la gestión de competencias: una mirada desde la formación. Revista Iberoamericana de Educación, 37(2), 1-16. Recuperado en: https://core.ac.uk/download/pdf/78542990.pdf

Tene, Refugio Humberto; Preciado, Juan Flores y Pérez Cruz, Omar. (2008). Importancia de la internacionalización en el desarrollo de competencias profesionales, en los egresados de las escuelas de negocios. Presentado en XII Congreso Internacional de la Academia de Ciencias Administrativas, A.C. (ACACIA), CETYS Universidad, Tijuana, México.

Tenney, Elizabeth; Vazire, Simine y Mehl, Matthias. (2013). This examined life: The upside of self-knowledge for interpersonal relationships. PLOS ONE 8(7): e69605. DOI: http://doi.org/10.1371/journal.pone.0069605

Trejo López, Enrique. (2015) Perfil psicosocial de la persona emprendedora (tesis doctoral). Universidad de Valladolid, Facultad de Educación y Trabajo Social, España.

Tünnermann Bernheim, Carlos. (2003). La universidad latinoamericana ante los retos del siglo XXI. México D.F.: UDUAL.

Urbano Gil, Henrique. (2007). El enfoque etnometodologico en la investigación científica. Liberabit 13(13), 89-91. Recuperado de http://www.scielo.org.pe/scielo.php?pid=S1729$\underline{48272007000100011 \& \text { script }=\text { sci arttext }}$

Vallaeys, Francois; De la Cruz, Cristina, and Sasia, Pedro. (2009). Responsabilidad social universitaria: manual de primeros pasos. Inter-American Development Bank. 
Vázquez del Mercado, Marcelle Bruce. (2009). Globalización y educación superior en México. REencuentro. Análisis de Problemas Universitarios, (54), 83-90. Recuperado de https://www.redalyc.org/pdf/340/34012025008.pdf

Villa, Aurelio y Poblete, Manuel. (2008). Aprendizaje basado en competencias. Una propuesta para la evaluación de competencias genéricas. Madrid: Ed. Mensajero.

Villalón, Estela. (2017). La movilidad estudiantil en el proceso de internacionalización. Estrategias metodológicas para su estudio. Revista Española de Educación Comparada, 29, 297-314. Recuperado de http://espacio.uned.es/fez/view/bibliuned:reec-2017-numero29-5085

Vogt, Dawne y Colvin, Randall. (2005). Assessment of accurate self-knowledge. Journal of Personality Assessment, 84(3), 239-251. Recuperado de https://www.tandfonline.com/doi/abs/10.1207/s15327752ipa8403 03

Woodrufe, Charles. (1993). Assessment centres: identifying and developing competence. London: Institute of Personnel Management.

Yaniz, Concepción y Villardón, Lourdes. (2006). Planificar desde competencias para promover el aprendizaje. Bilbao: Mensajero. 
Revista indizada en

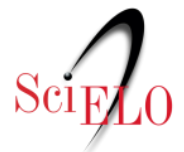

redalyc satindex

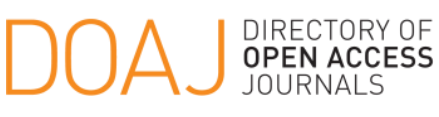

Distribuida en las bases de datos:

- Dialnet

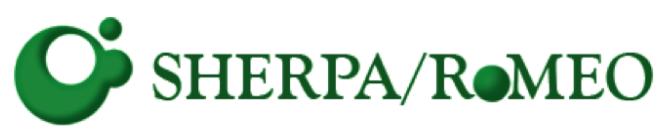

REDIB

Red Iberoamericana

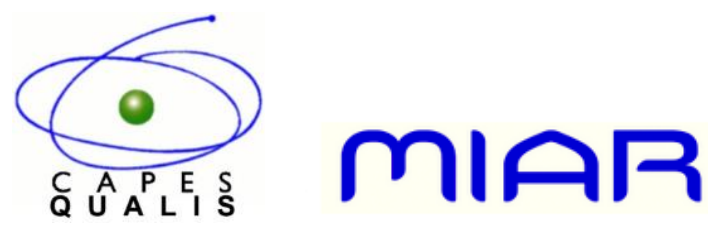

